\title{
Intraprofessional, Team-Based Treatment Planning for Oral Health Students in the Comprehensive Care Clinic
}

\author{
Nikos Mattheos, D.D.S., M.A.Sc. (Perio), Ph.D.; Mark Storrs, B.D.Sc., M.P.H.; Lea Foster, \\ B.D.Sc.; Theunis Oberholzer, B.D.Sc., M.Sc., Ph.D. \\ Abstract: In 2009, Griffith University School of Dentistry and Oral Health, in Queensland, Australia, introduced into its various \\ curricula the concept of team-based treatment planning (TBTP), aiming to facilitate intraprofessional, interdisciplinary training \\ and peer learning among its students. Fifty student teams were organized, each of which included students from three programs \\ (Dental Science, Oral Health Therapy, and Dental Technology) and three years of study (third-, fourth-, and fifth-year students). \\ This study prospectively evaluated the impact of TBTP on students' perceptions and attitudes towards teamwork and their role \\ in a team of peers. A total of 202 students who participated in fifty TBTP teams were prospectively surveyed at baseline and at \\ six and twelve months after introduction of TBTP. "Reliable" and "responsible" were reported to be the most important qualities \\ of both an effective team leader and member. Fifth-year students identified "hard-working" as an important quality of the ideal \\ leader as opposed to the fourth-year students who ranked "supportive" higher. Attitudes of the fifth-year students towards TBTP \\ appeared to have declined significantly from the previous years, while fourth-year students remained consistently more positive. \\ In addition, fourth-year students appeared more likely to enjoy working in a team and considered themselves more effective in a \\ team. No gender differences were observed, other than female students' appearing less confident to lead a team. It was concluded \\ that the function of student-directed interdisciplinary, intraprofessional treatment planning teams might pose disproportionate \\ strain on fifth-year students, impacting their attitudes to such modes of work.
}

Dr. Mattheos is Associate Professor of Implant Dentistry, Faculty of Dentistry, University of Hong Kong, Hong Kong SARChina; Dr. Storrs is Lecturer in General Dental Practice, School of Dentistry and Oral Health, Griffith University, Queensland, Australia; Dr. Foster is Lecturer, Comprehensive Care Clinic, School of Dentistry and Oral Health, Griffith University, Queensland, Australia; and Dr. Oberholzer is Professor, School of Dentistry and Oral Health, Griffith University, Queensland, Australia. Direct correspondence and requests for reprints to Dr. Nikos Mattheos, Oral Rehabilitation, Faculty of Dentistry, University of Hong Kong, Prince Philip Dental Hospital, 34 Hospital Road, 4/F Blk A19, Hong Kong, SAR-China; 852-2859-0526 phone; 852-2858-6114 fax; nikos@mattheos.net.

Keywords: oral health care, comprehensive care dental clinic, treatment planning, interprofessional education, intraprofessional education, team-based education, dental education

Submitted for publication 10/14/11; accepted 2/6/12

$\mathrm{M}$ odern health care practitioners are expected to practice in a rapidly changing environment where interdisciplinary and interprofessional collaboration of general practitioners, specialists, and allied health professionals has become the norm for effective patient management. Health professions education is consequently facing the challenge of training professionals with the wider ability to provide comprehensive patient care, while working in an interprofessional team.

Challenges historically associated with clinical training methods include fragmented disciplinary training and treatment planning. ${ }^{1-5}$ In addition, practical realities such as an increasing lack of adequate patient numbers can limit the actual student exposure to the necessary diversity of clinical cases. One of the recommendations proposed is the use of practice teams and expansion of peer teaching through increased collaboration between clinical health care professional programs. ${ }^{6}$ A number of universities have recently adopted team-based practice models, ${ }^{7-11}$ in which faculty members served as team leaders. However, only a few of those models have been peer-reviewed in the literature. ${ }^{12}$

The Griffith University School of Dentistry and Oral Health (GUSDOH) clinic in Queensland, Australia, was established in 2005 as part of a twelveschool health group. GUSDOH trains general dental practitioners as well as dental specialists, dental therapists/hygienists, dental technicians, and dental prosthetists, while the health group has programs for medical doctors, physiotherapists, midwifes, and other health care professionals. GUSDOH offers three professional qualifications through the following programs. A five-year Dental Science (D.Sc.) program leads to registrable qualifications as a dentist. A three-year Oral Health Therapy (O.H.T.) program leads to a registrable qualification as an oral 
health therapist. Although specific for Australia, this degree is comparable to that of a dental hygienist in North America. Finally, the three-year Bachelor of Dental Technology (D.T.) prepares students for working as dental technicians. All Griffith University health students attend the same program in their first year of studies. They are all exposed to structured teamwork as their education in the first two years is through problem-based learning.

In response to the current educational challenges, GUSDOH introduced to its curricula in 2009 the concept of team-based treatment planning (TBTP), in an attempt to facilitate intraprofessional (i.e., within the general oral health profession) and interdisciplinary training while emphasizing the importance of teamwork and peer learning strategies. The present study is part of a wider evaluation framework of the model; it aims to prospectively evaluate the impact of TBTP on students' perceptions and attitudes towards teamwork and their role in a team of peers.

\section{Materials and Methods}

\section{Team-Based Treatment Planning}

In February 2009, the school introduced TBTP into its Comprehensive Care Dental Clinic (CCDC), where students treat patients beginning in their third year of studies. Students were organized randomly in clinical groups consisting of one third-year, one fourth-year, and one fifth-year dental student, as well as a third-year oral health therapy student and when possible a dental technology student. Each group had a minimum of four and a maximum of five students.

The fifth-year student chaired the team, while the fourth-year student was responsible for coordinating the distribution of clinical procedures and following up on the progress of patient treatments undertaken by members of the team. The third-year students rotated as secretaries of the team. The secretary's duties included keeping the minutes of the meetings and ensuring timely information was sent to all members. Student groups held regular meetings, the frequency of which was determined by the team.

All patients seeking treatment in the GUSDOH clinic were initially screened for suitability by a staff member. Patients appropriate for treatment by these students were then allocated to a TBTP team. A comprehensive examination was conducted by a third- or fourth-year dental student. The clinical and radiographic examination, photographs, and all relevant data necessary for diagnosis and treatment planning were brought by the examining student to the next meeting of the TBTP team. In this meeting, the students collectively discussed all examined patients and decided on three treatment plan alternatives (preliminary treatment plans) for each patient; no tutor was present. All preliminary treatment plans were then finalized at a separate team session under the supervision of a tutor. Once the final treatment plan was approved, treatment procedures were distributed among the student members according to their competence and expertise level, as directed by the learning objectives of each clinical year. For example, a basic gingivitis treatment was performed by the oral health therapy student, while a single-rooted root canal treatment was performed by a fourth-year dental student and a molar root canal treatment was delegated to a fifth-year dental student. Specific guidelines were made available to the teams as to which type of treatments students from each program can undertake. However, the teams were responsible for distributing the procedures among their members without the involvement of a tutor.

\section{Survey Instrument}

Guided by the aims of the study, we developed individual statements for the survey instrument and organized them into three groups: descriptors of a successful team member/team leader, descriptors of the effectiveness of teamwork, and descriptors of personal engagement in a team. After consulting three senior faculty members to ensure the face validity of the statements, we selected thirty statements that best reflected the aims of the study. A questionnaire with three distinct sections was organized. The questionnaire was piloted with sixteen recent dental graduates to assess its content and layout. This validation procedure included one focus group discussion with two groups of eight students after completion of the questionnaire. The validation process focused on identifying linguistic and semantic accuracy; eliminating overlapping, controversial, and confusing descriptors; and ensuring the words were consistently used and easy to comprehend.

The questionnaire included a short preface collecting student demographic data. Section A requested students' perceptions of the most important qualities for a successful team member and a team leader. Students were asked to select the four most 
important qualities of a team member and leader from a list of twenty descriptors. Section B investigated the perceived impact of teamwork in treatment planning as compared to the previous situation (working alone) through agreement/disagreement with five statements as expressed in a $100 \mathrm{~mm}$ visual analogue scale (VAS). Section C investigated individual perceptions of the students with regard to their personal role and effectiveness as part of a team. This included agreement/disagreement with ten statements on a five-point Likert scale ( $1=\mathrm{I}$ very much agree, $2=\mathrm{I}$ agree, $3=\mathrm{I}$ neither agree nor disagree, $4=\mathrm{I}$ disagree, and $5=\mathrm{I}$ very much disagree). The study received ethics approval from the Griffith University Human Research Ethics Committee.

At baseline, three-hour introductory sessions were held with all third-, fourth-, and fifth-year students prior to the beginning of the academic year. At the end of these sessions, the questionnaire was distributed to the students, and they returned it on the same occasion. Completion of the questionnaire was voluntary and anonymous. At the end of the first semester (six months) and the end of the year (twelve months), the same questionnaire was distributed after the last lecture to the respective year of study.

Descriptive statistics were used to analyze student data. Nonparametric analyses were used in section A (Pearson's chi-square, Fisher's exact test) and section C (Kruskal-Wallis, Mann-Whitney) due to the ordinal nature of the data. Section B was analyzed with Kruskal-Wallis and Wilcoxon signed rank test, as normal distribution of collected data could not be assumed. Means and standard deviation of $\mathrm{mm}$ scores in the VAS (section B) were analyzed. All measurements in $\mathrm{mm}$ were rounded to the nearest $\mathrm{cm}$ and expressed in a value from 0 to 10 . The significance level for all tests was $p=0.05$.

The third-year students were comprised of participants in three separate programs (D.Sc., O.H.T., and D.T.), who had shared much of their basic science, biological, and health sciences coursework at this point in their studies. The D.Sc. cohort was much larger in number than the cohorts from the other two programs, so all third-year students' data were analyzed as one group.

\section{Results}

The distribution of the sample is shown in Tables 1, 2, and 3. The response rate was calculated by considering the total number of students at base- line, six months, and twelve months for each of the student year levels.

Section A. The four most highly ranked qualities for a team member and for a team leader are shown in Tables 4 and 5, respectively. Student responses that selected more than four descriptors in this section were excluded. With regards to the qualities of a team member versus that of a team leader for all students collectively, "hard-working" was a significantly more important quality for a team member $(p<0.05)$, while "knowledgeable" was significantly more important for a team leader $(\mathrm{p}<0.05)$.

The quality "knowledgeable" declined significantly at six and twelve months amongst the fifth-year D.Sc. students $(p=0.001)$. At the same time (twelve months), third-year students were more likely to choose "knowledgeable" as an important quality than both fifth-year $(p<0.0001)$ and a composite group of fourth- and fifth-year students $(\mathrm{p}=0.001)$ (Table 6). The quality "supportive" appeared consistently higher amongst third-year than fourth- or fifth-year students, but failed to reach significance. No significant gender differences were observed.

"Hard-working" was ranked significantly higher by both fifth-year students and the composite grouping of fourth- and fifth-year D.Sc. students compared to all third-year students at baseline $(\mathrm{p}=0.04)$ and six months $(\mathrm{p}=0.04$ and 0.02 respectively). "Supportive" and "fair" were consistently more important qualities as expressed by all thirdyear students, although "fair" declined significantly at six and twelve months for third- $(p=0.04)$ and fourth- $(\mathrm{p}=0.005)$ year students (Table 7). Again, there was no significant difference between genders.

Section B. The summative response from students from all years in relation to the impact of team-based treatment planning are shown in Table 8 . Four of the five statements suggest a significant decline in positive attitudes over time, with the majority of the decline taking place between baseline and the first six months. When we examined each year of study separately, we found no statistically significant change amongst third-year students, but there was a prospective significant decline in three of the statements for the fourth-year and two of the statements for the fifth-year D.Sc. students (Table 9).

Section C. Collectively, there appeared to be no significant prospective change in self-perceptions with regards to teamwork and working alone (Table $10)$. When each individual year was examined prospectively, the confidence (statement $6, \mathrm{p}=0.03$ ) and willingness (statement $8, \mathrm{p}=0.01$ ) of third-year stu- 
Table 1. Distribution of the 2009 student cohort at three survey intervals, by number and percentage

\begin{tabular}{lcccc} 
& Baseline & 6 Months & 12 Months & $\begin{array}{c}\text { Total Number } \\
\text { by Year }\end{array}$ \\
\hline Year 3 & $58(55.2 \%)$ & $55(52.4 \%)$ & $46(43.8 \%)$ & 105 \\
Year 4 & $22(41.5 \%)$ & $35(66.0 \%)$ & $37(69.8 \%)$ & 53 \\
Year 5 & $17(38.6 \%)$ & $33(75.0 \%)$ & $26(59.1 \%)$ & 44 \\
Total by interval & $97(48.0 \%)$ & $123(60.9 \%)$ & $109(54.0 \%)$ & 202
\end{tabular}

Note: Year 3 included third-year dental (D.Sc.), oral health therapy (O.H.T.), and dental technology (D.T.) students. Year 4 included fourth-year D.Sc. students. Year 5 included fifth-year D.Sc. students.

Table 2. Distribution according to program of study, by number and percentage

\begin{tabular}{|c|c|c|c|c|}
\hline & Baseline & 6 Months & 12 Months & $\begin{array}{c}\text { Total Number } \\
\text { by Program }\end{array}$ \\
\hline D.Sc. & $83(47.0 \%)$ & $116(65.9 \%)$ & $101(57.4 \%)$ & 176 \\
\hline O.H.T. & $10(76.9 \%)$ & $6(46.2 \%)$ & $6(46.2 \%)$ & 13 \\
\hline D.T. & $4(30.8 \%)$ & $1(7.7 \%)$ & $2(15.4 \%)$ & 13 \\
\hline Total by interval & $97(48.0 \%)$ & $123(60.9 \%)$ & $109(54.0 \%)$ & 202 \\
\hline
\end{tabular}

Table 3. Distribution according to gender, by number

\begin{tabular}{lccccccc}
\multicolumn{2}{c}{ Baseline } & \multicolumn{2}{c}{6 months } & \multicolumn{2}{c}{12 months } \\
\hline & Male & Female & Male & Female & Male & Female & Total \\
\hline D.Sc. 3 & 17 & 27 & 16 & 32 & 14 & 24 & 79 \\
D.Sc. 4 & 8 & 14 & 15 & 20 & 14 & 23 & 53 \\
D.Sc. 5 & 5 & 12 & 14 & 19 & 11 & 15 & 44 \\
O.H.T. & 2 & 8 & 2 & 4 & 2 & 4 & 13 \\
D.T. & 2 & 2 & 48 & 75 & 42 & 67 & 13 \\
Total & 34 & 63 & & & & & 202
\end{tabular}

dents to lead a group appeared to decline significantly and so did their confidence in being effective as team members ( statement $1, \mathrm{p}=0.02$ ). On the contrary, the confidence of fourth-year students as effective team members appeared to rise significantly (statement 1 , $\mathrm{p}=0.02$ ). There was a significant gender difference in the area of leading a team, as females appeared to be less confident than males in their ability to lead a team effectively (Table 11: s6, Baseline $\mathrm{p}=0.04,12 \mathrm{~m}$ $\mathrm{p}=0.01$ ), less likely to enjoy leading a team (Table 11: $\mathrm{s} 7$, Baseline $\mathrm{p}=0.03,12 \mathrm{~m} \mathrm{p}=0.01$, and less likely to volunteer to lead a team (Table 11: s8, Baseline $\mathrm{p}=0.02,12 \mathrm{~m} \mathrm{p}=0.04)$.

When the responses of the third-year students were compared to those of the combined fourth- and fifth-year students, significant differences were found (Table 12). In brief, the third-year students appeared to enjoy working in a team more than the combined fourth- and fifth-year students after six and twelve months, while the combined fourth- and fifth-year students reported believing themselves to be more effective in leading a team at baseline and six months, but not after twelve months.

Significant differences for third- and fourthyear students concerning self-perceptions comparing teamwork and working alone are shown in Table 13. There were no significant differences for fifth-year students in this section.

\section{Discussion}

There are four major characteristics of the TBTP structure. The teams are 1) intraprofessional, involving students from the three oral health programs; 2) multilevel, involving students at different 
Table 4. Four most frequently reported important qualities of a successful team member as perceived by all students in study

\begin{tabular}{|c|c|c|c|c|c|c|c|c|c|}
\hline \multicolumn{4}{|c|}{ Baseline $(\mathrm{n}=88)$} & \multicolumn{3}{|c|}{6 Months $(n=113)$} & \multicolumn{3}{|c|}{12 Months $(n=106)$} \\
\hline & & Number & Percentage & & Number & Percentage & & Number & Percentage \\
\hline 1 & Responsible & 57 & $64.7 \%$ & Reliable & 76 & $67.2 \%$ & Reliable & 73 & $68.8 \%$ \\
\hline 2 & Hard-working & 43 & $48.8 \%$ & Responsible & 67 & $59.2 \%$ & Responsible & 70 & $66.0 \%$ \\
\hline 3 & Reliable & 43 & $48.8 \%$ & Hard-working & 47 & $41.5 \%$ & Hard-working & 50 & $47.1 \%$ \\
\hline 4 & Supportive & 35 & $39.7 \%$ & Displays initiative & 37 & $32.7 \%$ & Displays initiative & e 31 & $29.2 \%$ \\
\hline 4 & & & & & & & Supportive & 31 & $29.2 \%$ \\
\hline
\end{tabular}

Note: Responses that selected more than four qualities were excluded.

Table 5. Four most frequently reported important qualities of a successful team leader as perceived by all students in study

\begin{tabular}{|c|c|c|c|c|c|c|c|c|c|}
\hline \multicolumn{4}{|c|}{ Baseline $(\mathrm{n}=90)$} & \multicolumn{3}{|c|}{6 Months $(n=115)$} & \multicolumn{3}{|c|}{12 Months $(n=104)$} \\
\hline & & Number & Percentage & & Number & Percentage & & Number & Percentage \\
\hline 1 & Knowledgeable & 59 & $65.5 \%$ & Responsible & 67 & $58.7 \%$ & Responsible & 63 & $60.5 \%$ \\
\hline 2 & Responsible & 52 & $57.7 \%$ & Knowledgeable & 65 & $57.0 \%$ & Knowledgeable & 55 & $52.8 \%$ \\
\hline 3 & Displays initiative & e 31 & $34.4 \%$ & Reliable & 47 & $41.2 \%$ & Reliable & 51 & $49.0 \%$ \\
\hline 4 & Reliable & 30 & $33.3 \%$ & Supportive & 47 & $41.2 \%$ & Displays initiative & e 40 & $38.0 \%$ \\
\hline
\end{tabular}

years in their studies; and 3) peer-managed/peeradministered, encouraging the independence of the teams and peer-determination of the flow of teamwork. They also involve 4) distribution of clinical work among team members, in which treatment of a patient might require the collaboration of two or three students, simulating an intraprofessional team. Team-based practice models have been implemented in a number of health professions schools, facilitating clinical reasoning and skills, communication skills, teamwork, and self-directed learning. In those models, faculty members served as team leaders. ${ }^{7-9}$

Faculty shortages at GUSDOH precipitated a modification of existing models, so that faculty team leaders were replaced with fifth-year dental science students as team leaders. However, one faculty member was assigned as clinical teams coordinator to monitor and facilitate the TBTP structure. This strategic choice aimed to reinforce the responsibility of the students and strengthen peer learning. ${ }^{13,14}$ In addition, providing a staff member at all fifty TBTP team meetings would not have been feasible given available human resources at the school. The lack of academic and teaching staff members is an increasing problem faced by dental schools throughout Australia, but also in the United States and many countries of Europe. The reasons for this decreasing number of faculty members are multiple and may be related to specific professional and academic conditions in each country. Although it is beyond the scope of this article to address this problem, it is without doubt one of the major concerns within dental education worldwide and requires the urgent collaboration of universities, governments, and professional bodies.

In terms of practical function, the system appears to have properly facilitated the patient flow and provision of treatments in the GUSDOH clinic. Fifty teams operated throughout the year without any major malfunctions. No situations were encountered that demanded intervention from the responsible faculty members or reallocation of teams or team members or that threatened to interrupt the function of any of the teams. During the academic year, 4,294 patients received treatment, a figure higher than the year before. The distribution of patients to the appropriate level of students appeared more streamlined, as the students were able to more easily select the appropriate treatment for their level.

The first six months of implementing the TBTP system proved to be a challenge in terms of logistics, and frequent troubleshooting was required. A formal university policy document was published with di- 
Table 6. Important qualities for a team member: differences between years of study

\begin{tabular}{|c|c|c|c|c|c|c|c|}
\hline & \multicolumn{2}{|c|}{ Baseline } & \multicolumn{2}{|c|}{6 Months } & \multicolumn{2}{|c|}{12 Months } & \multirow[b]{2}{*}{ p-value* } \\
\hline & Number & Percentage & Number & Percentage & Number & Percentage & \\
\hline \multicolumn{8}{|l|}{ Knowledgeable } \\
\hline Third year & $23 / 52$ & $44 \%$ & $18 / 51$ & $34 \%$ & $16 / 44$ & $35 \%$ & 0.6 \\
\hline Fourth year & $7 / 20$ & $35 \%$ & $11 / 32$ & $34 \%$ & $9 / 37$ & $24 \%$ & 0.5 \\
\hline Fifth year & $6 / 16$ & $37 \%$ & $6 / 30$ & $20 \%$ & $0 / 25$ & 0 & $<0.0001^{* *}$ \\
\hline 3 vs $4+5$ p-value* & 0.2 & & 0.3 & & 0.001 & & \\
\hline 3 vs 5 p-value* & 0.2 & & 0.2 & & 0.001 & & \\
\hline \multicolumn{8}{|l|}{ Supportive } \\
\hline Third year & $23 / 52$ & $44 \%$ & $19 / 51$ & $34 \%$ & $17 / 44$ & $39 \%$ & 0.7 \\
\hline Fourth year & $8 / 20$ & $40 \%$ & $9 / 32$ & $28 \%$ & $9 / 37$ & $24 \%$ & 0.4 \\
\hline Fifth year & $5 / 16$ & $31 \%$ & $6 / 30$ & $20 \%$ & $5 / 25$ & $20 \%$ & 0.6 \\
\hline 3 vs $4+5$ p-value* & 0.2 & & 0.2 & & & 0.1 & \\
\hline 3 vs 5 p-value* & 0.5 & & 0.1 & & & 0.1 & \\
\hline
\end{tabular}

Table 7. Important qualities for a team leader: changes for each year of study

\begin{tabular}{|c|c|c|c|c|c|c|c|}
\hline & \multicolumn{2}{|c|}{ Baseline } & \multicolumn{2}{|c|}{6 Months } & \multicolumn{2}{|c|}{12 Months } & \multirow[b]{2}{*}{$\mathrm{p}$-value } \\
\hline & Number & Percentage & Number & Percentage & Number & Percentage & \\
\hline \multicolumn{8}{|l|}{ Fair } \\
\hline Third year & $18 / 54$ & $33 \%$ & $9 / 54$ & $16 \%$ & $6 / 43$ & $14 \%$ & 0.04 \\
\hline Fourth year & $7 / 20$ & $35 \%$ & $1 / 31$ & $3 \%$ & $9 / 35$ & $26 \%$ & 0.005 \\
\hline Fifth year & $2 / 16$ & $12 \%$ & $8 / 30$ & $26 \%$ & $3 / 26$ & $11 \%$ & 0.3 \\
\hline 3 vs $4+5$ p-value & 0.2 & & 0.9 & & 0.2 & & \\
\hline 3 vs $5 p$-value & 0.2 & & 0.3 & & 0.9 & & \\
\hline \multicolumn{8}{|l|}{ Supportive } \\
\hline Third year & $20 / 54$ & $37 \%$ & $26 / 54$ & 48 & $19 / 43$ & $44 \%$ & 0.4 \\
\hline Fourth year & $6 / 20$ & $30 \%$ & $10 / 31$ & 32 & $9 / 35$ & $26 \%$ & 0.8 \\
\hline Fifth year & $3 / 16$ & $19 \%$ & $13 / 30$ & 43 & $7 / 26$ & $26 \%$ & 0.01 \\
\hline 3 vs $4+5$ p-value & 0.7 & & 0.4 & & 0.9 & & \\
\hline 3 vs $5 p$-value & 0.3 & & 0.9 & & 0.1 & & \\
\hline \multicolumn{8}{|l|}{ Hard-working } \\
\hline Third year & $10 / 54$ & $18 \%$ & $13 / 54$ & $24 \%$ & $12 / 43$ & $28 \%$ & 0.4 \\
\hline Fourth year & $7 / 20$ & $35 \%$ & $13 / 31$ & $42 \%$ & $13 / 35$ & $35 \%$ & 0.8 \\
\hline Fifth year & $7 / 16$ & $44 \%$ & $14 / 30$ & $46 \%$ & $7 / 26$ & $26 \%$ & 0.2 \\
\hline 3 vs $4+5$ p-value & 0.04 & & 0.02 & & & 0.7 & \\
\hline 3 vs 5 p-value & 0.04 & & 0.04 & & & 0.8 & \\
\hline
\end{tabular}

rections on the functions of the treatment planning team and obligations of its members. An online "organization" was created in Griffith University's Learning Content Management System devoted to the TBTP; it offered resources, discussion boards, and quick access to the academic coordinator of the TBTP system for urgent troubleshooting. The majority of the initial problems had to do with timetables or the availability of rooms for meetings. The teams at times had to meet outside normal university 
Table 8. Means of student responses (mean all students, mean 3rd years, mean 4 th +5 th years) to the impact of teambased treatment planning at baseline, six, and twelve months follow-up by year of study

1. As compared to working alone, I expect treatment planning in teams to be:

Less effective $=0$ to More effective $=10$

\begin{tabular}{lccccccc} 
& All & SD & $\mathrm{n}$ & $\mathrm{p}(\mathrm{KW})$ & $3 \mathrm{rd}$ & 4+5th & $\mathrm{p}(\mathrm{W})$ \\
\hline Baseline & 7.4 & 2 & 95 & 0.0006 & 7.9 & 6.7 & 0.04 \\
6 months & 6.2 & 2.5 & 123 & & 7.2 & 5.3 & 0.0001 \\
12 months & 6.2 & 2.8 & 109 & & 7.9 & 4.9 & 0.0001
\end{tabular}

2. As compared to working alone, I expect treatment planning in teams to be:

Inferior learning experience $=0$ to Superior learning experience $=10$

\begin{tabular}{lccccccc} 
& All & SD & $\mathrm{n}$ & $\mathrm{p}(\mathrm{KW})$ & $3 \mathrm{rd}$ & 4+5th & $\mathrm{p}(\mathrm{W})$ \\
\hline Baseline & 7.7 & 1.9 & 95 & 0.0005 & 8 & 7.3 & 0.01 \\
6 months & 6.7 & 2.3 & 123 & & 7 & 6.5 & 0.1 \\
12 months & 6.5 & 2.6 & 109 & & 7.3 & 6 & 0.02
\end{tabular}

3. As compared to working alone, I expect treatment planning in teams to be:

Less enjoyable $=0$ to More enjoyable $=10$

\begin{tabular}{lccccccc} 
& All & SD & $\mathrm{n}$ & $\mathrm{p}(\mathrm{KW})$ & 3rd & 4+5th & $\mathrm{p}(\mathrm{W})$ \\
\hline Baseline & 7.1 & 2.1 & 95 & 0.0005 & 7.4 & 6.5 & 0.01 \\
6 months & 6 & 2.1 & 123 & & 6.2 & 5.8 & 0.2 \\
12 months & 5.9 & 2.5 & 109 & & 6.5 & 5.5 & 0.09
\end{tabular}

4. As compared to working alone, I expect treatment planning in teams to be:

More difficult $=0$ to Easier $=10$

\begin{tabular}{lcccccccc} 
& All & SD & $\mathrm{n}$ & $\mathrm{p}(\mathrm{KW})$ & 3rd & 4+5th & $\mathrm{p}(\mathrm{W})$ \\
\hline Baseline & 6.2 & 2.6 & 95 & 0.3 & 6.7 & 5.5 & 0.12 \\
6 months & 5.9 & 2.5 & 123 & & 5.9 & 5.8 & 0.5 \\
12 months & 5.7 & 2.7 & 109 & & 6.1 & 5.4 & 0.1
\end{tabular}

5. As compared to working alone, treatment planning in teams is:

Less related to real-life working environments $=0$ to Closer to real-life working environments $=10$

\begin{tabular}{lccccccc} 
& All & SD & $\mathrm{n}$ & $\mathrm{p}(\mathrm{KW})$ & $3 \mathrm{rd}$ & 4+5th & $\mathrm{p}(\mathrm{W})$ \\
\hline Baseline & 6.6 & 2.2 & 95 & 0.005 & 6.8 & 6.3 & 0.6 \\
6 months & 5.6 & 2.2 & 123 & & 6 & 5.3 & 0.07 \\
12 months & 6 & 2.1 & 109 & & 6.3 & 5.7 & 0.1
\end{tabular}

Note: First column (All) presents summative means of all students; fifth and sixth columns present means of 3rd year and 4th+5th year students respectively (descriptive statistics).

$p(K W)=$ Kruskal-Wallis chi-squared showing significant change in positive attitudes over the three time intervals studied

$\mathrm{p}(\mathrm{W})=$ Wilcoxon signed ranks test showing significant differences between $3 \mathrm{rd}$ and 4 th +5 th year students over the same time intervals.

hours. In addition, the limited availability of small rooms with access to patient management software often meant that the teams had to meet in the clinic around treatment bays. Such practical and logistic limitations caused significant concerns especially in the first six months and may have affected students' attitudes reported here.

The results of this study suggest an overall significant decline in students' expectations/confidence in the TBTP model over the course of their educa- tion. Two factors are important for the interpretation of this decline. First, this decline mainly existed among the fourth- and fifth-year students, while the third-year students were significantly more positive and remained consistent in their attitudes. Second, this decline was concentrated in the first six months rather than being consistently spread across the whole year. This concentration might suggest an expiring novelty effect, as students at baseline possibly had inflated expectations for a model that was presented 
Table 9. Student response to the impact of team-based treatment planning: differences in attitude scores for each year of study

1. As compared to working alone, I expect treatment planning in teams to be: Less effective $=0$ to More effective $=10$

\begin{tabular}{lcccc} 
& Baseline Mean & 6 Months Mean & 12 Months Mean & $\begin{array}{c}\text { Kruskal-Wallis } \\
\text { One-Way ANOVA }\end{array}$ \\
\hline Third year & $7.91(1.8)$ & $7.24(2.4)$ & $7.95(2)$ & 0.1 \\
$\mathrm{n}$ & 57 & 55 & 46 & 0.019 \\
Fourth year & $7.62(1.4)$ & $6.31(2.0)$ & $6.13(2.16)$ & 37 \\
$\mathrm{n}$ & 21 & 35 & $3.31(2.32)$ & 0.007 \\
Fifth year & $5.71(2.3)$ & $4.38(2.1)$ & 26 &
\end{tabular}

2. As compared to working alone, I expect treatment planning in teams to be: Inferior learning experience $=0$ to Superior learning experience $=10$

\begin{tabular}{lcccc} 
& Baseline Mean & 6 Months Mean & 12 Months Mean & $\begin{array}{c}\text { Kruskal-Wallis } \\
\text { One-Way ANOVA }\end{array}$ \\
\hline Third year & $8.07(1.8)$ & $7.22(2)$ & $8.47(1.5)$ & 0.1 \\
$\mathrm{n}$ & 57 & 55 & 46 & 0.0004 \\
Fourth year & $8(1.55)$ & $7.09(1.7)$ & $6.24(1.8)$ & 37 \\
$\mathrm{n}$ & 21 & 35 & $3.88(2.4)$ & 0.005 \\
Fifth year & $6.4(2.3)$ & $4.78(2.2)$ & 26 &
\end{tabular}

3. As compared to working alone, I expect treatment planning in teams to be: Less enjoyable $=0$ to More enjoyable $=10$

\begin{tabular}{lcccc} 
& Baseline Mean & 6 Months Mean & 12 Months Mean & $\begin{array}{c}\text { Kruskal-Wallis } \\
\text { One-Way ANOVA }\end{array}$ \\
\hline Third year & $7.46(1.8)$ & $6.87(2.3)$ & $7.39(2.1)$ & 0.1 \\
$\mathrm{n}$ & 57 & 55 & 46 & 0.018 \\
Fourth year & $7.19(1.8)$ & $5.86(2.3)$ & $5.54(2.19)$ & 37 \\
$\mathrm{n}$ & 21 & 35 & $4.15(2.3)$ & 0.0796 \\
Fifth year & $5.82(2.3)$ & $4.84(2.1)$ & 26 &
\end{tabular}

Note: Numbers in parentheses represent standard deviation.

as an innovation. The novelty effect may have been stronger for fourth- and fifth-year students, as up to this point they had experienced only the prior system of individually planning treatments with their supervisors. Consequently, the TBTP system was perceived to be a novelty, aiming to improve function and effectiveness, and that may have raised some high expectations. On the other hand, the thirdyear students were just entering the clinic without any previous experience in treatment planning and without any particular expectations.

The fifth-year students were significantly less positive towards the TBTP than the students in other years; however, they did not change their individual attitudes towards working in a team and leading a team as the data from section $\mathrm{C}$ indicate. This could suggest that decline in the attitudes towards TBTP might be a result of increased workload and stress, rather than a decrease in willingness to work in a team. In the absence of a tutor, fifth-year students were the most experienced resources for treatment planning and therefore were disproportionately important for the function of the team. Although third-year students could turn to the team for feedback, fifth-year students often felt they could not expect answers to their questions within the team and needed the feedback of a tutor to resolve their questions. Another practical implication is that fifthyear students were very often attending outplacement rotations in satellite clinics, which proved to affect the function of the team but also the workload and stress of the fifth-year students. On the other hand, fifth-year students benefited most by being able to select treatment procedures of appropriate complex- 
Table 10. Median of all students' responses comparing teamwork self-perceptions at baseline, six, and twelve months

\begin{tabular}{|c|c|c|c|c|c|}
\hline & Statement & Baseline & 6 Months & 12 Months & p-value \\
\hline s1 & I believe I am effective when working in a team. & 2 & 2 & 2 & 0.1 \\
\hline s2 & I enjoy working in a team. & 2 & 2 & 2 & 0.4 \\
\hline s3 & I prefer to work in a team when possible. & 3 & 3 & 3 & 0.7 \\
\hline s4 & I prefer to work alone when possible. & 3 & 3 & 3 & 0.8 \\
\hline s5 & I enjoy working alone. & 3 & 3 & 2.5 & 0.6 \\
\hline s6 & I believe I am effective in leading a team. & 2 & 2 & 2 & 0.08 \\
\hline s7 & I enjoy leading a team. & 3 & 3 & 2 & 0.1 \\
\hline s8 & I would gladly lead a team. & 3 & 3 & 2 & 0.1 \\
\hline s9 & Effective teamwork requires meeting in person. & 2 & 2 & 2 & 0.2 \\
\hline s10 & Effective teamwork can be conducted online, without meeting in person. & 3 & 3 & 3 & 0.3 \\
\hline
\end{tabular}

Table 11. Significant differences between median gender responses concerning self-perceptions comparing teamwork and working alone at baseline, six, and twelve months

\begin{tabular}{|c|c|c|c|c|c|c|c|c|c|c|}
\hline & & & Baseline & & & 6 Months & & & 2 Month & \\
\hline & Statement & Male & Female & p-value & Male & Female & p-value & Male & Female & p-value \\
\hline 3 & I prefer to work in a team when possible. & $2(2.4)$ & $3(2.8)$ & 0.05 & $3(2.5)$ & $3(2.8)$ & 0.1 & $3(2.4)$ & $3(2.7)$ & 0.1 \\
\hline 6 & I believe I am effective in leading a team. & $2(2.1)$ & $2(2.5)$ & 0.04 & $2(2.4)$ & $2(2.5)$ & 0.7 & $2(2)$ & $2(2.3)$ & 0.01 \\
\hline 7 & I enjoy leading a team. & $2(2.3)$ & $3(2.7)$ & 0.03 & $3(2.6)$ & $3(2.7)$ & 0.5 & $2(2.2)$ & $3(2.5)$ & 0.01 \\
\hline 8 & I would gladly lead a team. & $2(2.2)$ & $3(2.7)$ & 0.02 & $3(2.6)$ & $3(2.5)$ & 0.6 & $2(2.1)$ & $2(2.4)$ & 0.04 \\
\hline 10 & $\begin{array}{l}\text { Effective teamwork requires meeting } \\
\text { in person. }\end{array}$ & $2(1.7)$ & $2(1.8)$ & 0.7 & $2(2)$ & 2(1.8) & 0.3 & $2(2.3)$ & $2(1.8)$ & 0.04 \\
\hline
\end{tabular}

Note: p-value determined by Mann-Whitney non-parametric test. Medians are reported, followed by means in parentheses.

ity to their level, as they were able to select complex cases from the large pool of patients allocated to the team. In light of this, it comes as no surprise that the fifth-year students perceived an ideal team leader as "hard-working" much more than the third-year students, who reported seeing the ideal leader quality as "supportive." These findings may represent differences in attitudes and perceptions between team members, which in certain circumstances could affect teamwork and educational quality outcomes. ${ }^{15}$ Challenges may occur when student members of the team are holding divergent values concerning task performance and teamwork. ${ }^{16-18}$ Factors reported to affect the interaction and team performance included individual characteristics of members, team culture/ climate, team processes to manage challenges, building a climate of trust, developing shared goals, and coordination of work processes. ${ }^{18-21}$ Differences in the students' attitudes and perceptions with regards to teamwork mainly appeared related to their year of study.
With regards to both effective team leaders and members, there was a consistently high ranking of two rather similar qualities: "responsible" and "reliable." Although the two words may overlap in connotation, the validation process suggested a clear distinction between the two. "Responsible" was mostly perceived as "acknowledge own duties, act to fulfil tasks and accountable," while "reliable" was understood to mean "dependable, assured to undertake expected tasks."

In our study, females appeared to be significantly less confident than males in their ability to lead a team. In practice, however, twenty-two of the fifty teams were chaired by females with no suggestion of inferior team function throughout the twelve months. Whether female perceptions represented a true lack of confidence or were related to other factors needs to be further investigated.

In most of the programs, the response rate exceeded 50 percent, with the exception being the dental technology students whose response rate was 
Table 12. Significant differences between median $3^{\text {rd }}$ year and $4^{\text {th }}+5^{\text {th }}$ year student responses concerning self-perceptions on teamwork at baseline, six, and twelve months

Baseline $\quad 6$ Months $\quad 12$ Months

I believe I am effective when working in a team.

Third year

$2(2)$

$2(1.8)$

0.06

p-value

I enjoy working in a team.

Third year

Fourth and fifth years

p-value

prefer to work in a team when possible.

Third year

Fourth and fifth years

p-value

I prefer to work alone when possible.

Third year

Fourth and fifth years

p-value

I believe I am effective in leading a team.

Third year

Fourth and fifth years

p-value
$2(2.1)$

$2(2.1)$

0.7

$3(2.6)$

$3(2.8)$

0.2

$3(2.9)$

$3(2.9)$

0.6

$2(2.5)$

2 (2.1)

0.01
2 (1.9)

2 (2.2)

0.008

2 (1.7)

2 (2.1)

0.001

2 (1.9)

2 (2.4)

0.0005

2 (2.4)

0.001

2 (2.4)

$2(2.3)$

3 (2.9)

3 (2.8)

0.002

0.004

$3(3.1)$

$\begin{array}{cc}3(2.8) & 3(2.7) \\ 0.2 & 0.01\end{array}$

$\begin{array}{cr}3(2.8) & 3(2.7) \\ 0.2 & 0.01\end{array}$

0.2

2 (2.2)

2 (2.2)

0.9

Note: p-value determined by Mann-Whitney non-parametric test. At Baseline, 6 months, and 12 months, medians are reported, followed by means in parentheses. Statistical significance was calculated on the basis of medians; means are provided only as an indication of the direction of change (increase/decrease) where significant change was found.

Scale for responses: $1=\mid$ very much agree, $2=\mid$ agree, $3=\mid$ neither agree nor disagree, $4=\mid$ disagree, $5=\mid$ very much disagree.

Table 13. Significant differences in median students' responses for each year of studies concerning self-perceptions comparing teamwork and working alone at baseline, six, and twelve months

Baseline

6 Months

12 Months

p-value

Year 3

I believe I am effective when working in a team.

$2(2)$

$2(2.5)$

$3(2.7)$

$2(1.7)$
$2(1.9)$

$3(2.6)$

$3(2.6)$

$2(2.1)$
$2(1.7)$

$2(2.2)$

$2(2.2)$

$2(2.1)$
0.02

0.03

0.01

Year 4

I believe I am effective when working in a team.

d by means in parentheses.

consistently low. The numbers of dental students make a dominance of the dental program inevitable in the sample, and the lower response rates especially from dental technology students make it impossible to investigate differences in attitudes among programs. These may be seen as limitations of our study. The results therefore reflect merely the attitudes of the dental students, and it remains unknown if any significant differences would exist between dental and oral health therapy students' attitudes. Reasons for not responding might vary among the programs or years of study. As the questionnaires were distributed and collected during lecture sessions, students who were absent at those occasions did not have another opportunity to complete the questionnaires. A culture of overevaluation is sometimes said to have caused survey fatigue among students. Being a young school, GUSDOH has conducted a number of student evaluations aiming to receive feedback on all programs and courses, resulting in a significant number of 
questionnaires being distributed around the end of the semester. In some cases, low participation might reflect a lower engagement with the TBTP, which could be a factor in the case of the dental technology students since due to the nature of the program their involvement was not as active as for the dental and oral health therapy students.

It would have been interesting to correlate students' attitudes with data from the teams' logbooks and investigate whether the frequency of meetings, for example, had an impact on students' attitudes and acceptance of the TBTP model. As the majority of students chose to remain anonymous for the purpose of the questionnaires, any correlation with team logs was not possible. However, this might be a worthy investigation for future evaluations of the model.

The challenge raised with this study is that, in such a multilevel teamwork model, the fifth-year students appear to be the weakest link of the concept. They receive an increased responsibility/workload, while at the same time they might feel they are the ones who benefit the least from the team interaction. Although no fifth-year student was reported to systematically neglect his or her responsibilities towards the team, further improvements of the TBTP model are needed to ensure that those students can see a clear benefit from their contribution to the TBTP. This is not an easy challenge to solve, especially when considering that fifth-year students are in general fewer in numbers than fourth-year students. Increased support and incentives must be provided to fifth-year students for their contribution to the team. ${ }^{20,21}$ Possibly the curriculum could be structured in such a way that leading a team would be a formal curriculum activity, reflected also in the assessment. This would allow for the the TBTP to be part of the overall fifth-year students' scheduled workload. Alternative adjustments might be to rotate the role of the chairperson among the members of the team or increase the amount of involvement of tutors, without affecting the peer character of the teams.

\section{REFERENCES}

1. Gerzina TM, McLean T, Fairley J. Dental clinical teaching: perceptions of students and teachers. J Dent Educ 2005;69(12):1377-84.

2. Allen WR. Dental education in the European Union. Br Dent J 2005;199:33-4.

3. Eriksen HM, Bergdahl J, Bergdahl M. A patient-centred approach to teaching and learning in dental student clinical practice. Eur J Dent Educ 2008;12:170-5.

4. Fugill M. Teaching and learning in dental student clinical practice. Eur J Dent Educ 2005;9:131-6.
5. DePaola D, Slavkin HC. Reforming dental health professions education: a white paper. J Dent Educ 2004;68(11): 1139-50.

6. Kassebaum DK, Hendricson WD, Taft T, Haden NK. The dental curriculum at North American dental institutions in 2002-03: a survey of current structure, recent innovations, and planned changes. J Dent Educ 2004;68(9):914-31.

7. University of Minnesota Programs and Student Admissions. Doctor of Dental Surgery program. At: www. dentistry.umn.edu/programs admissions/home.html. Accessed: October 14, 2011.

8. University of Missouri-Kansas City. Prospective dental student FAQs: what is it like to be a dental student? At: http://dentistry.umkc.edu/Future Students/faqs.html. Accessed: October 14, 2011.

9. University of Kentucky College of Dentistry. 2008-09 clinic manual. At: www.mc.uky.edu/Dentistry/students/ dmd/ClinicManual08-09.pdf. Accessed: October 14, 2011.

10. University of Pennsylvania. Penn dental medicine: academic programs and admissions. At: www.dental.upenn. edu/academic programs admissions/dmd program/ dmd_curriculum. Accessed: October 14, 2011.

11. University of Sydney. Bachelor of Oral Health: frequently asked questions. At: http://sydney.edu.au/dentistry/student/boh.php\#FAQ. Accessed: October 14, 2011.

12. Lloyd-Jones G, Ellershaw J, Wilkinson S, Bligh JG. The use of multidisciplinary consensus groups in the planning phase of an integrated problem-based curriculum. Med Educ 1998;32:278-82.

13. Chambers D. Problem-based learning and authentic tasks for IT leadership development. Presentation at ASET Conference, Melbourne, July 7-10, 2002.

14. Krishnan S, Vale CM, Gabb R. Making PBL teams successful: a study on student diversity in a first-year electrical engineering programme. Proceedings of the 1st Research Symposium on Problem-Based Learning, Aalborg, Denmark, June 30-July 1, 2008.

15. Stalmeijer RE, Gijselaers WHI, Wolfhagen IHAP, Harendza S, Scherpbier AJJA. How interdisciplinary teams can create multidisciplinary education: the interplay between team processes and educational quality. Med Educ 2007;41:1059-66.

16. Van den Bossche P, Gijselaers WH, Segers MSR, Kirschner PA. Social and cognitive factors driving teamwork in collaborative learning environments: team learning beliefs and behaviours. Small Group Res 2006;37(5):490-521.

17. Van den Bossche P. Minds in teams: the influence of social and cognitive factors on team learning. Ph.D. thesis, Maastricht University, 2006.

18. Edmondson A. Psychological safety and learning behaviour in work teams. Adm Sci Q 1999;44:350-83.

19. De Dreu CKW, Weingart LR. Task versus relationship conflict, team performance, and team member satisfaction: a meta-analysis. J Appl Psychol 2003;88(4):741-9.

20. Van der Vegt G, Emans B, Van der Vliet E. Motivating effects of task and outcome interdependence in work teams. Group Organ Manage 1998;23(2):124-43.

21. Van Knippenberg D, De Dreu CKW, Homan AC. Workgroup diversity and group performance: an integrative model and research agenda. J Appl Psychol 2004;89(6):1008-22. 